\section{MCQ papers}

Dear Sirs

I do not think that the examiners' reply (Bulletin, May $1987,11,168-169)$ to concerns, particularly those raised by Dr Williams (Bulletin, May 1987, 11, 167) about the MCQ part of the MRCPsych examination should be the final word on the subject. Although the MCQ format is a reliable method of examining candidates, it is not necessarily the most valid, just as operational criteria do not necessarily improve the validity of psychiatric diagnoses, and every effort needs to be made to ensure that MCQ questions are of good quality. I am not convinced that the Working Party for Review of the MRCPsych considered the resource implications of their recommendation that the number of MCQ papers for the two parts of the examination should be increased from two to three.

MCQ questions are difficult to frame. ${ }^{1} \mathrm{~A}$ high proportion of questions needs to be set for the first time in an examination, partly to ensure that the number of questions that would be recognised from previous examinations is low, and I should be interested to know what proportion of questions is newly set by the examiners. The bank from which questions are drawn for the examination needs to be large and continually expanding.

The policy of not publishing past MCQ papers leads to inequalities in the level of preparation of candidates because some trainees have managed to obtain copies of libraries of questions produced from recollections of previous papers. If past papers were officially published, the bank of questions for future examinations would need to be larger. It may not be necessary to publish the answers to the questions as well as the questions themselves to even out the advantages of candidates, but surely it is possible for the answers to specimen papers to be published, even if it means losing those questions from the bank forever. I think it could be generally appreciated that the answers given are correct only in the present state of knowledge of psychiatry and, in fact, it would be interesting to see how understanding of a particular issue in psychiatry changes over the years. Maybe, however, the examiners' reticence to publish the answers to questions does reflect their unwillingness to submit those questions and answers to quality control by psychiatrists in general.

There was no discussion in the Working Party report of the advantages and disadvantages of the different types of multiple choice question. In particular, the one-from-five and multiple completion formats (see Anderson, 1982, Chapter 1 for a description) ${ }^{1}$ test judgement and discrimination, qualities obviously important in a psychiatrist, to a greater extent than the multiple true/false variety. However, these less well known formats are more difficult to set, and each stem does not produce five questions. To produce the same number of testable elements more questions have to be set, thus necessitating an increase in the bank of questions, with implications for resources in addition to the extra work involved in preparing these questions. The multiple true/ false format has been favoured because it is easier and pro- duces more questions, yet that does not imply it is more valid.

Are the examiners able to reassure trainees that they have sufficient resources to be able to produce a sufficiently large bank of high quality questions to ensure a valid MCQ examination? Failure to publish past papers and answers, at least, to the specimen papers may well be taken as an indication that they cannot, as will an unwillingness to consider other formats apart from multiple true/false, since formats which test judgement and discrimination would seem particularly appropriate for the MCQ paper, at least in clinical topics. I am not suggesting that the MCQ papers are replaced, but that they should be of a high standard and continually improving, as they seem to be, in fact, from my own experience. The actual paper I sat for my Part I examination did seem of higher quality than some of the questions I had seen circulating amongst colleagues before the examination. I hope that the questions continue to improve.

D. B. DOUble

Fulbourn Hospital

Cambridge

REFERENCE

ANDerson J. (1982) The Multiple Choice Question in Medicine. 2nd Edition. London: Pitman.

\section{Dear Sirs}

Nobody would claim that any MCQ paper is the 'most valid' method for examining candidates. It is complementary to other aspects of the examination - written papers, clinicals and orals. Its aim is to test for certain kinds of factual information, and the hope is that within these limits all its questions will be valid. We agree with Dr Double's point that efforts are necessary to ensure that the questions are broad in scope, correct, unambiguous and fair. The recently formed Working Party on the MCQ is striving to achieve and maintain this state of affairs. It is casting the net widely for new questions, or for material from which new questions may be derived. All the Divisions and Sections of the College, and many other people, have been asked. Moreover, each question is carefully reviewed by the Working Party before being placed in the Bank. Every paper is carefully scrutinised during its preparation by the Examinations Sub-Committee. The preliminary Test and Membership Examination together contained $120 \mathrm{MCQs}$. The new Parts I and II have 150. The resources are available.

The proportion of completely new questions is rising, and we hope will continue to rise. But an adequate MCQ bank will have many questions which may be selected for use many times over, perhaps with significant modifications. It should have as low a sampling ratio as possible, and its papers should not be predictable.

Dr Double urges that the number of questions recognisable from previous examination should be low. We agree. In our previous letter we cautioned against attempting to memorise past questions. There can be many different MCQs on the same or closely similar topics. 
Dr Double mentioned that the bank needs to be large and continually expanding. That point has already been covered. We agree. In addition every question needs to be kept under review, and its past performance scrutinised. It needs to be modified and refined to keep up with the times and to ensure the greatest possible clarity and relevance. In a good bank, few questions go for long without modification.

Dr Double suggests that past papers should be published. if this were done, many people might hope to predict the contents of the next paper by studying a set of past papers. This is not a good way to learn psychiatry. Matters to do with the examination should not inculcate bad habits. Trainees may have 'libraries of questions'. These may be worthless for many reasons. We touched on this in our previous letter.

The same considerations attach to the matter of providing answers to specimen papers. The examination should subserve the educational function. It is not good educational practice to encourage students to contemplate stale MCQs and their answers. Nor would this activity help with passing the examination. if anybody wishes to see how particular issues in psychiatry become differently understood over the years the best thing they can do is study the literature.

We do not see the MCQs as calling for 'quality control' in Dr Double's sense. Psychiatrists in general are the producers: as many as possible of the Members and Fellows of the College (and others) submit questions. The Working Party studies them, and selects and alters as necessary to reach an unambiguous and fair product. The Examinations Sub-Committee appointed by the Court of Electors takes responsibility for each paper as a whole.

Much thought has been given to the possibility of using different types of multiple choice questions. All the medical Royal Colleges use the multiple true/false format. It is in some ways easier to set and administer. It is also good for candidates to know that all MCQs follow a uniform pattern. Mixing in different types of format would be confusing, and add enormously to the expense of marking. The candidates' knowledge, judgement and discrimination are tested [only to a limited extent] by MCQs. Other parts of the examination evaluate these as well as other abilities, such as clinical reasoning, in differing but complementary ways.

Professor R. H. CAWLEY

Chief Examiner

Deputy Chief Examiner

Professor H. G. MORGAN

Chairman, MCQ Working Party

Dr O. HILL

\section{Continuing medical education}

\section{DEAR SIRS}

We are writing with reference to Dr Peter Brook's paper on this subject. (Bulletin, February 1987, 11, 38-42).

In the questionnaire, respondents were asked to tick which of the few named journals they read. The journals did not include any of the most widely read journals covering the subject of child psychiatry. There was no mention, for example, of the Journal of Child Psychology and Psychiatry. the leading journal in our field, nor of Developmental Medicine and Child Neurology for those with particular interest in paediatric liaison, chronic handicap etc, nor of the Journal of American Academy of Child Psychiatry, another international scientific journal, nor of any of the journals concerned with treatment in child psychiatry such as Family Process, Family Therapy, etc. It is thus erroneous to conclude that child and adolescent psychiatrists read less than others in different sub-specialties since no mention of the main journals had been made in that particular question.

When the questionnaire was sent, the poor design of the question concerning journals read was pointed out to Dr Brook. Also, when the first draft of this paper was circulated through the College, this matter was discussed with Dr Brook but the inaccuracies were not corrected and the paper that was published in the Bulletin is seriously misleading.

Consultant Child Psychiatrist

ANN GATH

Previously Secretary

Child and Adolescent Psychiatry Section

I. KolviN

\section{Chairman of the Child and}

Adolescent Psychiatry Section

\section{DeAR'Sirs}

We are sorry to learn that Professor Kolvin and Dr Gath believe that the question concerning journals was poorly designed and that in consequence our paper was seriously misleading. If we had included every important journal in every specialty of psychiatry the list would have been enormous-Kolvin and Gath named six for child psychiatry alone - and the answers would have been of little value.

The paper did not pretend to constitute a comprehensive survey of the reading habits of psychiatrists, whether generalists or working in the specialties. Of necessity the enquiry was brief, merely asking about the use made of four important journals, namely, the British Medical Journal, Lancet and two major general psychiatric journals. The latter two were chosen because we assumed that they were likely to be read by psychiatrists in all specialties. They have both recently contained papers by distinguished child psychiatrists including Professor Kolvin himself, while both he and Dr Gath act as assessors for the British Journal of Psychiatry. We find it difficult to believe that Child Psychiatrists, more than other sub-specialists, should be expected to throw their British Journal of Psychiatry unread into the waste paper basket.

P. BROOK

Fulbourn Hospital

R. WAKEFORD

Cambridge 